\title{
The Impact of Combined Oral Sildenafil and Inhaled Nitric Oxide for Treating Persistent Pulmonary Hypertension of the Newborn: A Single Center Experience
}

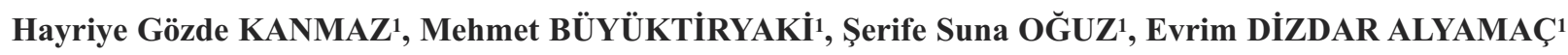 \\ Fatma Nur SARI', Fuat Emre CANPOLAT'1, Nurdan URAS ${ }^{1}$ \\ Ankara, Turkey
}

ABSTRACT

OBJECTIVE: We aimed to compare the effect of the combined therapy, sildenafil and inhaled nitric oxide with inhaled nitric oxide monotherapy for the treatment of Pulmonary Hypertension of the Newborn.

STUDY DESIGN: Newborn infants (gestational age greater than 34 weeks) who were diagnosed with pulmonary hypertension between December 2008 and 2010 were retrospectively evaluated. Group I $(n=14)$ received monotherapy with inhaled nitric oxide and Group II $(n=9)$ received combined therapy with inhaled nitric oxide and oral sildenafil. Primary outcome was to compare the duration of inhaled nitric oxide therapy between groups.

RESULTS: Demographic characteristics were similar between the groups. Combination therapy was associated with early weaning of inhaled nitric oxide ( $4.8 \pm 1.5$ vs. $13.5 \pm 7.6$ hours). The duration of inhaled nitric oxide therapy was slightly shorter in combined therapy group (75[24-125] vs. 109[24-210] hours), however, the difference was insignificant $(p=0.2)$. The incidence of mortality and neonatal outcomes were similar between the groups $(p>0.05)$.

CONCLUSION: Combined therapy did not result in shorter duration of inhaled nitric oxide therapy. Further well designed and larger studies that will elucidate the benefits of combination therapies and optimal therapy whereinhaled nitric oxide is not available are warranted.

Keywords: Pulmonary hypertension, Newborn, Sildenafil, Inhaled nitric oxide

Gynecol Obstet Reprod Med 2017;23(2):100-104

\section{Introduction}

Persistent pulmonary hypertension of the newborn (PPHN) is a potentially life-threatening condition which is associated with increased pulmonary vascular resistance, ventilation-perfusion mismatch, and right-to-left shunting resulting

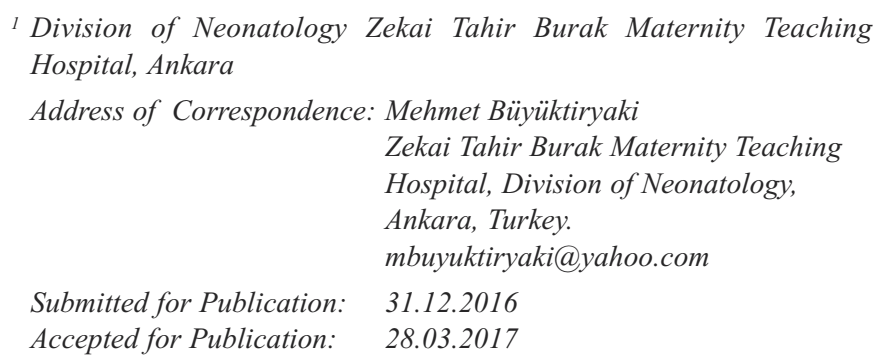

\begin{tabular}{|c|c|}
\hline & Access this article online \\
\hline $\begin{array}{c}\text { Quick Response Code: } \\
\text { Website: www.gorm.com.tr }\end{array}$ \\
\cline { 2 - 3 }
\end{tabular}

How to cite this article: Kanmaz HG. Büyüktiryaki M. Oğuz ŞS. Dizdar Alyamaç E. Sar FN. Canpolat FE. Uras N. The Impact of Combined Oral Sildenafil and Inhaled Nitric Oxide for Treating Persistent Pulmonary Hypertension of the Newborn: A Single Center Experience. Gynecol Obstet Reprod Med 2017;23(2):100-4 in systemic hypoxia. The prevalence of PPHN has been estimated at 1.9 per 1000 live births (1).

The primary goal of therapy is selective pulmonary vasodilatation. Nitric oxide (NO) is one of the selective pulmonary vasodilators and synthesized from L-arginine by nitric oxide synthase. Currently, the most common therapy in severe PPHN is inhaled nitric oxide (iNO) which causes potent, selective, sustained pulmonary vasodilatation (2-4). Despite a favorable efficacy; outcomes for infants treated with iNO are not universally helpful. Approximately 30-40\% of infants treated with iNO do not respond (5). The reasons for poor response to iNO are not well known, it may be related to endothelial dysfunction, down-regulation of endogenous nitric oxide, or multiple etiologies of PPHN. So that, no single treatment is effective in all cases (6).

Sildenafil, a phosphodiesterase type 5 inhibitor, is an agent that has been shown to selectively reduce pulmonary vascular resistance in both animal models and adult humans. It has also been reported to be successful in the treatment of infants with PPHN $(7,8)$. Combination therapies are of considerable interest for treatment which fails to respond to monotherapy. 
Although this approach has worked well in adults with pulmonary hypertension (PAH), there are a few studies using combination therapy in newborn infants with PPHN (9).

The objective of this study was to compare the effects of combined therapy (sildenafil and iNO) versus monotherapy with iNO in newborn infants with PPHN on neonatal morbidities and mortality.

\section{Material and Method}

\section{Study population}

Newborn infants who were diagnosed with clinical signs and symptoms of PPHN from December 2008 to December 2010 were retrospectively evaluated. Zekai Tahir Burak Maternity Teaching Hospital, Neonatal Intensive Care Unit is a tertiary and also reference center for iNO therapy. Therefore, the outborn infants who have symptoms of neonatal Hypoxic Respiratory Failure (nHRF) were transferred to our center. Among these, infants with severe nHFR and clinical and/or echocardiographic PPHN were included in this study. Infants who have severe asphyxia, congenital heart defect and congenital diaphragm hernia were excluded from the study. This study was approved by the local ethics committee.

Patients were analyzed in two groups based on intervention. Group I consisted of patients who were treated with iNO monotherapy. Group II consisted of patients who were treated with combined therapy (iNO and sildenafil). Birth weights (g), gestational ages (week), gender, mode of delivery, being inborn/outborn, age at the time of NICU admission (hour), type of respiratory support required (before/after iNO), severity of illness (by oxygenation index), length of stay in hospital (day) were obtained from medical records and nurses' bedside flow sheet. Also, recognized maternal, prenatal, and postnatal risk factors were recorded. Detail of the treatments included age at iNO therapy (hours) commenced; time of weaning, duration of iNO therapy was obtained from medical records.

\section{Definition and criteria of $\mathbf{n H R F} / \mathbf{P P H N}$}

Neonatal hypoxic respiratory failure was defined as Oxygenation Index (OI) greater than 25 . OI is calculated as: $\mathrm{OI}=\left[\left(\mathrm{FIO}_{2} \mathrm{X} \mathrm{Paw}\right) / \mathrm{PaO}_{2}\right] \times 100$ where Paw is mean airway pressure.

Infants manifesting hypoxemia that is disproportional to the degree of parenchymal lung disease and also have a difference of $5 \%$ or more in pre-ductal and post-ductal $\mathrm{SpO}_{2}$ levels were diagnosed as clinical PPHN. For definitive diagnosis of PPHN two-dimensional color Doppler echocardiography was performed with a GE Vivid 7Pro, 10S transducer (GE Healthcare, Salt Lake City, Utah) by an experienced pediatric cardiologist. Echocardiographic evidence of PPHN was defined as an estimated peak systolic pulmonary-artery pressure that was higher than $35 \mathrm{~mm} \mathrm{Hg}$ as indicated by a tricuspid regurgitated jet flow, a right-to-left shunt on ductus arteriosus or a patent foramen ovale.
Guideline of iNO Therapy and Delivery of Gas iNO gas (Orya Med Ltd, Izmit, Turkey) was delivered from 1000-ppm cylinder. NO was introduced into inhalation limb of the ventilator circuit close to the endotracheal tube with the iNO Delivery System (iNO ventilator circuit, SLE Limited, UK), thus mixing with gas in the ventilator circuit. NO and Nitrogen dioxide $\left(\mathrm{NO}_{2}\right)$ were measured with monitor SLE 3600 INOSYS (SLE Limited, UK). Initially iNO was administered at $20 \mathrm{ppm}$. Blood gases and methemoglobin levels were checked three times per day during iNO treatment.

Response to the treatment was described as follow;

1. Positive response: An increase in pre-ductal $\mathrm{SpO}_{2}$ $(>92 \%)$ within 1 hour after commencement of iNO therapy

2. Dependency of iNO: Clinical and/or laboratory deterioration (increased $\mathrm{FiO}_{2}$ requirement $>0.2$ and/or decrease in $\mathrm{PaO}_{2}$ ) during the weaning of $\mathrm{iNO}$ treatment, positive response to the maintenance of iNO therapy

Once the infant had a positive response, iNO weaning was initiated when $\mathrm{FiO}_{2}$ has been weaned to $<0.6$. The dose was decreased in decrements of $5 \mathrm{ppm}$ as frequently as every 4 hours if the infant's condition was stable or pre-ductal $\mathrm{SpO}_{2}$ was at least $92 \%$ and pre-post ductal $\mathrm{SpO}_{2}$ difference was less than $<5 \%$. If the criteria were not met, the dose of iNO had been maintained at $20 \mathrm{ppm}$ for the following 24 hours and at the end of the 24 hour, the patient was evaluated again for weaning criteria.

\section{Sildenafil therapy}

Infants who get sildenafil as a first line therapy due to unavailability of iNO treatment and then transferred to our center were evaluated. Infants who met the inclusion criteria and received iNO treatment right after admission along with sildenafil were analyzed. Sildenafil was administered via a nasogastric tube at a dose of $1 \mathrm{mg} / \mathrm{kg} /$ day. After weaning from the ventilator and iNO therapy, sildenafil was gradually decreased and withheld over a week.

\section{Outcomes}

Our Primary outcome was the duration of iNO therapy in both groups. Secondary outcomes were the mortality rates and morbidities such as duration of hospitalization and supplemental oxygen dependency.

\section{Statistical analysis}

Statistical analyses were performed by using the SPSS 15.0 statistical package (SPSS; Chicago, III). P $<.05$ was considered to indicate a significant difference. The results were expressed as means of Standard Deviations (SD) for normally distributed variables and as median and ranges for categorical variables. We evaluated categorical values using the twotailed Chi-square and Fisher's exact test (when the chi-square test does not hold due to the use of low expected cell counts compared to these proportions in different groups). 
Continuous variables were compared with two tailed t-test or Kruskal-Wallis test.

\section{Results}

During the study period, a total of 43 infants were diagnosed as nHRF/PPHN. Sixteen of them were excluded from the study (10 of them were less than 34 weeks, 2 of them had congenital heart disease, 4 of them had congenital diaphragmatic hernia). Only 23 neonates met the inclusion criteria. In group I, 14 infants and in group II, 9 infants were analyzed.
The patient characteristics and major risk factors are listed in table 1. Except gender demographic characteristics were similar in both groups. Male gender predominance was observed in group II. Primary causes of PPHN and co-morbidities were listed in table 2. The most common cause was meconium aspiration syndrome in both groups. Comparison of oxygenation indices and MV support between groups are summarized in table 3 . Initial iNO administration time was significantly longer in Group II in comparison with Group I (5.1 \pm 8.2 vs. $21.3 \pm 36 \mathrm{~h} ; \mathrm{p}=0.01)$.

Table 1: Demographic characteristics of the groups

\begin{tabular}{lccc}
\hline Characteristics & iNO monotherapy $(\mathrm{n}=14)$ & Combined therapy $(\mathrm{n}=9)$ & $\mathrm{p}$ \\
\hline Maternal age (years) * & $32.1 \pm 4.4$ & $29.6 \pm 6.4$ & 0.2 \\
Vaginal birth (n, \%) & $9(64)$ & $3(37.5)$ & 0.4 \\
Gestational age (weeks) * & $38.2 \pm 1.3$ & $38.8 \pm 1.4$ & 0.8 \\
Birth weight (g) * & $2763 \pm 672$ & $2895 \pm 845$ & 0.4 \\
Gender, Male (n, \%) & $3(21)$ & $6(75)$ & 0.03 \\
Apgar score $\dagger$ & & & \\
$\quad 1$ min & $5(1-7)$ & $7(2-7)$ & 0.5 \\
$\quad 5$ min & $7(4-9)$ & $7(4-9)$ & 0.5 \\
iNO administration time (h) & $4(1-13)$ & $19(6-36)$ & 0.01 \\
Surfactant administration $(\mathrm{n}, \%)$ & $9(64.3)$ & $5(62.5)$ & 0.9 \\
\hline
\end{tabular}

*mean \pm standard deviation tmedian (min-max), iNO: Inhaled nitric oxide, Combined therapy: iNO and sildenafil

Table 2: Primary diagnosis on NICU admission

\begin{tabular}{lll}
\hline Primary diagnosis & iNO monotherapy $(\mathrm{n}=14)$ & Combined therapy $(\mathrm{n}=9)$ \\
\hline Meconium aspiration syndrome $(\mathrm{n}, \%)$ & $5(35.7)$ & $3(33.3)$ \\
Perinatal asphyxia $(\mathrm{n}, \%)$ & $4(28.5)$ & $2(22.2)$ \\
Respiratory distress syndrome $(\mathrm{n}, \%)$ & $1(7.1)$ & $3(33.3)$ \\
Pneumonia $(\mathrm{n}, \%)$ & $3(21.4)$ & $1(11.1)$ \\
Idiopathic pulmonary hypertension $(\mathrm{n}, \%)$ & $1(7.1)$ & 0 \\
\hline
\end{tabular}

iNO: Inhaled nitric oxide, Combined therapy: iNO and sildenafil

Table 3: Comparison of oxygenation indices and mechanical ventilation support between groups

\begin{tabular}{|c|c|c|c|}
\hline & iNO monotherapy (14) & Combined therapy (9) & $p$ value \\
\hline \multicolumn{4}{|l|}{ Type of MV support before iNO therapy-n (\%) } \\
\hline - High-frequency oscillation & $5(35.7)$ & $1(12.5)$ & 0.12 \\
\hline - Conventional mechanical ventilation & $9(64.2)$ & $7(87.5)$ & 0.37 \\
\hline \multicolumn{4}{|l|}{ Type of MV support after iNOtherapy-n (\%) } \\
\hline - High-frequency oscillation & $8(57.1)$ & $7(87.5)$ & 0.76 \\
\hline - Conventional mechanical ventilation & $6(42.8)$ & $1(12.5)$ & 0.17 \\
\hline \multicolumn{4}{|l|}{ Blood gases values on NICU admission } \\
\hline $\mathrm{pH}^{*}$ & $7.21 \pm 0.1$ & $7.05 \pm 0.25$ & 0.06 \\
\hline $\mathrm{pCO} 2(\mathrm{mmHg}) *$ & $62.5 \pm 23$ & $67.7 \pm 22$ & 0.62 \\
\hline $\mathrm{pO} 2(\mathrm{mmHg}) *$ & $34.4 \pm 11.1$ & $38.4 \pm 13.0$ & 0.48 \\
\hline $\mathrm{Ol1}$ * & $44.9 \pm 21.3$ & $40.2 \pm 21.3$ & 0.66 \\
\hline $\mathrm{Ol} 2$ * & $25.7 \pm 5.6$ & $23.2 \pm 4.5$ & 0.78 \\
\hline
\end{tabular}

${ }^{*}$ mean \pm standard deviation, iNO: Inhaled nitric oxide, Combined therapy: iNO and sildenafil, OI: Oxygenation Index, pCO2: Partial carbon dioxide pressure, $\mathrm{pO}_{2}$ : Partial oxygen pressure, Ol1: Obtained right before administration of iNO, OI2: Obtained at the second hour of iNO treatment 
Combined therapy with sildenafil was significantly associated with earlier $(4.6 \pm 1.5$ vs. $13.6 \pm 7.5 \mathrm{~h} ; \mathrm{p}=0.01)$ and successful weaning of iNO treatment. Overall duration of iNO therapy was shorter in combined group [75 (24-125) vs 109 (24-210) h]. However, this difference was statistically insignificant (Table 4). The rate of mortality and morbidities (length of stay in hospital, discharge home with oxygen therapy) were similar between the groups (Table 4).

\section{Discussion}

The safety and efficacy of iNO for PPHN have been particularly well studied through large placebo-controlled trials (11-14). Despite efficacy and safety of iNO therapy, respond to the treatment is not unique since PPHN occurs in association with a diverse group of neonatal respiratory illnesses. In this retrospective cohort of infants with PPHN the most common cause was meconium aspiration syndrome in both combined and monotherapy groups and the other causes were distributed evenly in both groups.

Based on the multiple etiologies of PPHN, no single therapy is effective in all cases. Current novel and experimental therapies include alternative means of delivering NO, prostanoids, endothelin receptor antagonists, antioxidant therapy, and PDE-5 inhibitors etc. (15). Among the mentioned therapies both oral and intravenous sildenafil, a PDE-5 inhibitor, have been studied in term and late preterm neonates with PPHN and found to improve oxygenation and survival. Furthermore, our results supported that combined therapy also reduces the overall duration of the treatment and provides faster weaning from iNO. Mortality rates were lower in combined therapy group (22\%) when compared with monotherapy $(50 \%)$ even the combined therapy group were outborn patients who required transportation to get iNO treatment. This outcome did not reach to a statistically significance possibly due to low sample size.

Although our study was retrospective trial, this study showed that the duration of iNO therapy was significantly shorter in sildenafil and iNO combination therapy group. Also, combined therapy with sildenafil was associated with early weaning of iNO and a reduction in need for iNO therapy when compared to iNO monotherapy. This improvement may be explained as that different drugs or therapies fix the different mechanisms which are responsible for the pathogenesis of PPHN, such as heart failure, maldevelopment, or vascular remodeling. However, data about prophylactic administration of sildenafil and combination therapies in newborn infants are very limited. A multicenter, randomized clinical trial is required to test the efficacy of sildenafil in iNO-resistant PPHN.

Namachivayam et al. (16) demonstrated that single dose of oral sildenafil is effectively protected patients from rebound pulmonary hypertension who are on iNO therapy, in a prospective, randomized, controlled study. Similarly, to our results Lee et al. (17) reported that the use of oral sildenafil facilitates weaning from iNO therapy. Shah et al. (18) conducted a Cochrane meta-analysis and reported that Sildenafil in the treatment of PPHN has significant potential especially in resource limited settings. However, a large scale randomized trial comparing sildenafil with the currently used vasodilator, inhaled nitric oxide, is needed to assess efficacy and safety.

In an analysis of a small population of neonates with PPHN it is reported that, apart from different underlying pathological conditions, time of beginning of iNO therapy is a strong predictor of outcome (19). As iNO is not available in all neonatal units yet, it is of great interest to identify alternative therapies that could be used immediately after the diagnosis of PPHN, or even in the presence of a strong clinical suspicion, before the arrival of the baby to the referral center. In our study outcomes were comparable in inborn and outborn patients despite the combined therapy group received iNO significantly later that supports the idea that patients should get alternative therapies before transportation.

The main limitations of this study was its retrospective design and small sample size. Moreover, sildenafil was used in an off-label manner (po) in this study due to lack of iv form of

Table 4: Comparison of neonatal mortality and morbidities between groups

\begin{tabular}{|c|c|c|c|}
\hline Outcome & $\begin{array}{l}\text { iNO monotherapy } \\
\text { (14) }\end{array}$ & $\begin{array}{l}\text { Combined therapy } \\
\text { (9) }\end{array}$ & $\begin{array}{l}p \\
\text { values }\end{array}$ \\
\hline \multicolumn{4}{|l|}{ Death } \\
\hline - during iNO treatment $\mathrm{n}(\%)$ & $5(35.7)$ & $1(11.1)$ & 0.4 \\
\hline • overall n( \%) & $7(50)$ & $2(22)$ & 0.6 \\
\hline Lenght of stay in hospital for survivors (days) * & $20.3 \pm 6.8$ & $20.2 \pm 16.3$ & 0.6 \\
\hline \multicolumn{4}{|l|}{ Pulmonary outcome in survivors } \\
\hline - Discharge with supplemental oxygen, n(\%) & 0 & $1(11.1)$ & 0.5 \\
\hline - Discharge with no intervention, n (\%) & $7(50)$ & $6(66.6)$ & 0.8 \\
\hline Time of weaning from iNO therapy, $(\mathrm{h})$ * & $13.6 \pm 7.5$ & $4.6 \pm 1.5$ & 0.01 \\
\hline Duration of iNO therapy for survivors, (h) median & $109(24-210)$ & $75(24-125)$ & 0.2 \\
\hline
\end{tabular}


the drug. Sildenafil was not started simultaneously with iNO in the combined therapy group and the time gap between two therapies is heterogeneous in patients included. Results of these study should be evaluated carefully regarding all these limitations.

Our results suggest that combination therapy (with sildenafil and iNO) could be more effective to reduce iNO weaning time but has no effect on the overall duration of iNO therapy that is relatively expensive. These results need to be confirmed with further large, prospective well-designed trials comparing drug dosages, time of onset, rank of onset, and safety of drug-drug interaction.

\section{References}

1. Walsh-Sukys MC, Tyson JE, Wright LL, Bauer CR, Korones SB, Stevenson DK, et al. Persistent pulmonary hypertension of the newborn in the era before nitric oxide: practice variation and outcomes. Pediatrics 2000;105 (1): 14-20.

2. Oishi P, Fineman JR. Pulmonary Hypertension. Pediatr Crit Care Med 2016;17(8):140-5.

3. Stayer SA, Liu Y. Pulmonary hypertension of the newborn. Best Pract Res Clin Anaesthesiol 2010;24(3):37586.

4. Finer NN, Barrington KJ. Nitric oxide therapy for the newborn infant. Semin Perinatol 2000; 24(1):59-65.

5. Finer NN, Barrington KJ. Nitric oxide for respiratory failure in infants born at or near term. Cochrane Database Syst Rev 2006;(4):CD000399.

6. Steinhorn RH. Diagnosis and treatment of pulmonary hypertension in infancy. Early Hum Dev 2013;89(11):86574.

7. Steinhorn RH. Neonatal pulmonary hypertension. Pediatr Crit Care Med 2010;11(2):79-84.

8. Baquero H, Soliz A, Neira F, Venegas ME, Sola A. Oral sildenafil in infants with persistent pulmonary hypertension of the newborn: a pilot randomized blinded study. Pediatrics 2006;117(4):1077-83.

9. Dhariwal AK, Bavdekar SB. Sildenafil in pediatric pulmonary arterial hypertension. J Postgrad Med 2015;61 (3):181-192.
10. Ahsman MJ, Witjes BC, Wildschut ED, Sluiter I, Vulto AG, Tibboel D, et al. Sildenafil exposure in neonates with pulmonary hypertension after administration via a nasogastric tube. Arch Dis Child Fetal Neonatal Ed 2010; 95(2):109-14.

11. Roberts JD Jr, Fineman JR, Morin FC, Shaul PW, Rimar $\mathrm{S}$, Schreiber MD, et al. Inhaled nitric oxide and persistent pulmonary hypertension of the newborn. NEJM 1997; 336(9):605-10.

12. Clark RH, Kueser TJ, Walker MW, Southgate WM, Huckaby JL, Perez JA, et al. Low-dose nitric oxide therapy for persistent pulmonary hypertension of the newborn. Clinical Inhaled nitric oxide research Group. NEJM 2000;342(7):469-74.

13. Davidson D, Barefield ES, Kattwinkel J, Dudell G, Damask M, Straube R, et al. Inhaled nitric oxide for the early treatment of persistent pulmonary hypertension of the term newborn: A randomized, double-masked, placebo-controlled, dose response, multicenter study. Pediatrics 1998;101(3):325-34.

14. Neonatal Inhaled Nitric Oxide Study Group. Inhaled nitric oxide in full-term and nearly full-term infants with hypoxic respiratory failure. NEJM 1997;336(9):597-604.

15. Lakshminrusimha S, Konduri GG, Steinhorn RH. Considerations in the management of hypoxemic respiratory failure and persistent pulmonary hypertension in term and late preterm neonates. J Perinatol 2016;36(2):12-9.

16. Namachivayam P, Theilen U, Butt WW, Cooper SM, Penny DJ, Shekerdemian LS. Sildenafil prevents rebound pulmonary hypertension after withdrawal of nitric oxide in children. Am J Respir Crit Care Med 2006;174(9): 1042-7.

17. Lee JE, Hillier SC, Knoderer CA. Use of sildenafil to facilitate weaning from inhaled nitric oxide in children with pulmonary hypertension following surgery for congenital heart disease. J Intensive Care Med 2008;23(5):329-34.

18. Shah PS, Ohlsson A. Sildenafil for pulmonary hypertension in neonates. Cochrane Database Syst Rev 2011;(8): CD005494.

19. Nassi N, Daniotti M, Agostiniani S, Lombardi E, Favilli S, Donzelli GP. Sildenafil as "first line therapy" in pulmonary persistent hypertension of the newborn? J Matern Fetal Neonatal Med 2010;23(3):104-5. 